\title{
Hablando de resistencia y del ejercicio de la noviolencia en la experiencia comunitaria en candomblés
}

\author{
Maria Consuelo Oliveira Santos \\ Kàwé- Universidade Estadual de Santa Cruz, UESC \\ Emai: consol.oliveira@gmail.com
}

\begin{abstract}
Resumen: Terreiro de candomblé es un espacio afro-brasileño de resistencia como una forma de persistencia cultural, en defensa de un conocimiento integrador, complejo, envuelto en una exuberante estética simbólica, cuyos elementos culturales originarios de África son resignificados por medio de una cosmovisión dual sin ser disyuntiva. Es una comunidad que instituye la noción de familia-simbólica, valorando la solidaridad y la unión. La dimensión lúdica forma parte de los performances rituales que se integran a la noción de fiesta religiosa. El cuerpo tiene un gran protagonismo, implicando relaciones de intimidad con el orixá, y que suscita construcciones identitarias en la dinámica de una jerarquía sacralizada. Esta religión todavía no recibe la debida atención de muchos sectores de la sociedad brasileña, por no considerar que el candomblé construyó un saber que supera las cuestiones de la fe. Estudiar su epistemología puede posibilitarla comprensión yel reconocimiento de aspectos de la identidad nacional, en el ejercicio de la noviolencia, que aún son negados.
\end{abstract}

Palabras clave: candomblé, dualidad no dicotómica, corporalidad, poder sacralizado, resistencia/persistencia cultural.

\section{Speaking about resistance and the practice of nonviolence in the community experience in candomblés}

Abstract: Terreiro de Candomblé is an Afro Brazilian space of resistance, as a mode of cultural persistence in defense of an integrative knowledge, complex and involved in a exuberant symbolism. In its scope of action, the cultural elements from Africans are daily resignified by a dual worldview without any disjunction. It is a community that establishes the notion of a symbolic family, valuing solidarity and union. The playful dimension is part of the performances of the rituals who integrate the notion of religious celebration. The body has a leading role involving intimate relationships with the orixá, and raises identity constructions in the dynamics of a sacralized hierarchy. This religion has not yet received proper attention of Brazilian society, by not considering that the Candomblé has built a knowledge that goes beyond matters of faith. Studying its epistemology can enable the understanding and recognition of aspects of national identity, in the exercise of nonviolence, which are still denied.

Keywords: candomblé, duality without dichotomy, corporality, sacred power, cultural persistence/ resistance. 


\section{Falando de resistência y do exercício da nãoviolência a partir da experiência comunitária emcandomblés}

Resumo: Terreiro de candomblé é um espaço afro-brasileiro de resistência como uma forma de persistência cultural, em defesa de um conhecimento complexo e envolvido numa exuberante estética simbólica, cujos elementos culturais originários da África são resinificados por meio de uma cosmovisão dual sem ser disjuntiva. É uma comunidade que institui a noção de família-simbólica, valorizando a solidariedade e a união. A dimensão lúdica forma parte das performances rituais que se integram à noção de festa religiosa. $\mathrm{O}$ corpo tem um grande protagonismo, implicando relações de grande intimidade com o orixá, e que suscita construções identitárias na dinâmica de uma hierarquia sacralizada. Esta religião ainda não recebe a devida consideração por parte de muitos setores da sociedade brasileira, por não considerar que ocandomblé construiu um saber que ultrapassa a questão da fé. Estudar sua epistemologia pode possibilitar a compreensão e o reconhecimento de aspectos da identidade nacional, no exercício da nãoviolência, que ainda são negados.

Palavras-chave: candomblé, dualidade não dicotômica, corporalidade, poder sacralizado, resistência/persistência cultural.

\section{En parlant de résistance et de l'exercice de la non-violence à partir de l'expérience communautaire dans les candomblés}

Résumé: Terreiro Candomblé est un espace afro-brésilien de résistance come une forme de persistence culturel, en défense d'une connaissance intégrative, complexe et impliqué dans un exubérant symbolisme. Dans son champ d'action, les éléments culturels à origine africain sont resignifiés quotidiennement par une vision du monde duale, non disjonctive. Un Candomblé est une communauté qui établit la notion d'une famille symbolique, ainsi que la valorisation de la solidarité et l'union. La dimension ludique fait partie des performances rituelles qui se sont intégrées à la notion de fête religieuse. Le corps joue un rôle principal ce qui entraîne des relations d'intimité avec l'orixá et que suscite des constructions identitaires dans la dynamique d'une hiérarchie sacralisée. C'est religion ne reçoit l'attention méritée par part de beaucoup de secteurs de la société brésilienne, pour ne considérer pas que le candomblé a bâti un savoir qui dépasse les questions concernant la foi. L'étude de son épistémologie peut permettre la compréhension et la reconnaissance d'aspects de l'identité nationale, dans l'exercice de la nonviolence, lesquels sont déniés.

Mots clés: candomblé, dualité no dichotomique, corporalité, pouvoir sacré, résistance/persistence culturel.

\section{Introducción}

La construcción de saberes afro-brasileños nace en el seno de la violencia de la esclavitud. Seres humanos fueron forzados a dejar sus tierras, sus familias, sus culturas, por traficantes de personas entre los siglo XVI al XIX, periodo de la expansión esclavista en las américas. En el territorio brasileño, un ambiente hostil por la fuerza de un poder segregacionista, 
diversas etnias africanas utilizaron muchas estrategias de subsistencia, modos de negociación, en la defensa de elementos culturales transportados en sus cuerpos, resinificados y reinventados en convivencia con otras percepciones de realidad. El candomblé, una de las religiones afro-brasileñas, también llamado terreiro de candomblé o simplemente terreiro, posibilitó que se rememorase dinámicamente los valores de los diversos pueblos originarios de territorios africanos, resultando ser un punto de encuentro aglutinador de saberes y reconstrucción identitaria. Este espacio comunitario posibilitó, también, la recuperación de parte de los lazos rotos por la esclavitud en la vivencia de una familia-simbólica.

De acuerdo con Parés (2007), la consolidación de un conjunto de prácticas ritualistas, que posteriormente sería denominado Candomblé, se hizo posible debido a laconfluencia de diversos procesos complejos, sea sociales, políticos, económicos o culturales. Goldman (2005:1) sintetiza la diversidad que forma parte de esta religión:

Constituido aparentemente a partir del siglo XIX -al menos tal cual lo conocemos hoy-, el candomblé incluye también, en mayor omenor grado, elementos de cosmologías y prácticas indígenas, así como del catolicismo popular y delespiritismo de origen europeo. Se puede observar, igualmente, una bien acentuada diversidad entre los diferentes grupos de culto, diversidad vinculada a la región África de donde proviene la mayor parte del repertorio de cada grupo, así como a las modalidades e intensidades de sus conexiones "sincréticas" con otras tradiciones religiosas. (traducción propia)

Cuando empecé a realizar las primeras investigaciones en candomblés en el sur de Bahia, por medio de la observación participante, una de mis primeras preocupacionesfueen la dirección de comprender qué había tras el comportamiento y accionesde una gente que superó todo tipo de situaciones de opresión,con violencia física y simbólica, para continuar resistiendo, hasta el punto de proporcionar la expansión de terreiros por todo el país y con una tendencia a la transnacionalización de conocimientos, como se comprueba por la presencia de candomblés, actualmente, en otros países.

Percibí que la propia modalidad de conocimiento ha sido una herramienta de resistencia. La noción de un conocimiento integrador permitió que la gente construyera una vivencia de gran intimidad con la divinidad y que, para conseguir sus bendiciones, habría que realizar un trabajo en conjunto, en comunidad, en la concepción de communitas de Víctor Turner (1988 [1969]), cuando presenta que un grupo social enfatiza el sentimiento de igualdad, de solidaridad y de vivencia en comunión, en el cual todos los participantes están subordinados a las mismas normas.

Además, la comunidad en el candomblé se refuerza por los lazos de una familia-simbólica, que también denomino de comunidad-familia. La fuerza generada en estos grupos en la defensa de un saber, tiene una relación 
directa con la propia dignificación de sus participantes. En que peselos problemas de cualquier grupo en sí mismo así como con los demás, considerando una comunidad de candomblé es también un campo de embates, el propio grupo proporciona los mecanismos para la reconstrucción identitaria intersubjetiva, con la muerte y renacimiento simbólicos para la vivencia de una vida comunal, bajo iniciaciones específicas.

Canclini (2013:1) llama la atención que "la noción de resistencia es una de las más utilizadas menos analizadas en la retórica crítica”. Igualmente destaca que como ocurre con cualquier otro vocablo, "su sentido no se forma solamente por lo que su raízdicta, sino enarticulacióncon otros conceptos". En este sentido, la noción de resistencia requiere que se contemple en interrelación con otras áreas del conocimiento, locual amplia su alcance. Mientras Araújo (2014) llama la atención hacia el carácter polisémico, plural y ambiguo del término resistencia. Evidentemente que estos son los problemas frecuentes que los conceptos nos presentancuando pretendemos comprenderlos.

Confieso que aunque he utilizado el términoresistencia, en varias ocasiones, aun no lo he profundizado como debería, ni tampoco es mi pretensión lograrlo en este artículo. Ambiciono, eso sí, salir de la inercia y, para ello, voy aconsiderarel término resistencia como una forma de persistencia cultural, a partir de la construcción epistemológica, que se formó en laconfluencia de distintas miradas, valores, percepciones de pueblos africanos y sus descendientes en la formación del candomblé, en sur de Bahia.Mi intención es delimitarun tipo deresistencia en la defensa de un conocimiento, contrario al pensamiento disyuntor, y que, por cuenta de su especificidad, generó persecuciones, incomprensiones y prejuicios hacia los candomblés.

En este sentido, considero que los candomblés constituyen un factor de resistencia, coincidiendo con Barros y Teixeira (2000) y con Ferreti (1995:112) cuando defiende que la Casa das Minas, es un núcleo dinámico de resistencia cultural. Parés (2006:85) así expone sobre el tema: “ [...] los procesos de resistencia cultural de minorías étnicas o clases sociales subalternas, basados en el mantenimiento de valores y prácticas culturales diferenciados de aquellos de la cultura dominante, ofrecen mecanismos de luchas a aquellos individuos discriminados de las esferas del poder” (t.p.)

Pondré énfasis en la resistencia a partir de la construcción de un conocimiento afro-brasileñoy me acercaré a estudios que nos permiten repensar construcciones marcadas por las conocidas separaciones entre moderno-tradicional y colonizador-colonizado, que predisponen a la supremacíade una posición sobre las demás.Tampoco la intención es subrayar que los esclavos y sus descendientes siempre estuvieron en la condición de victimas o héroes, como ciertas historiografías exponen. Se sabe que en las construcciones sociales la existencia de negociaciones, tanto cuanto los conflictos, así como las acomodaciones entre las partes (Reis; Silva: 2005). 
Mi propósito es intentar evidenciar un tipo de conocimiento que seria difícil ser aceptado y/o comprendido por los esclavistas porque sus presupuestos no formaban parte de la epistemología dominante. Evidentemente que existía la negación de un saber por la existencia de la propia dominación en sí misma, del poder visible del colonizador sin la predisposición para a la escucha y al respeto a las construcciones que se erigían de estos sujetos. Pero, además de ello, los disfraces, las tácticas de uso, la transformación en secretos de ciertos aspectos y tantas otras estrategias eran movimientos para ocultar concepciones filosóficas y epistemológicas que estaban opuestas al modelo del poder vigente.

De este modo, hablar de resistencia nos remite a la noción de persistencia cultural, como ya hemos dicho anteriormente, o sea, de construcción y preservación dinámica de un modo de conocimiento y de una sociabilidad propia del candomblé. La vivencia de un saber integrador se hace mediante el ejercicio de no la noviolencia que, según Martínez (2004:2), es “[...] una forma de práctica socio-política, como todo un conjunto de estrategias y procedimientos de lucha, forcejeo y presión político-social”. Asimismo, señala que " $[\ldots]$ se trata de una construcción cultural, con dimensiones teórico-prácticas, que se encuentra en una fase histórico-conceptual de crecimiento y vitalidad, pero, también de discusión de sus fronteras y de su alcance” (ídem: 3). Siguiendo esta proposición, se observa que los grupos religiosos afrodescendientesconsiguieronasegurar su dignificación mediante la libertad de expresión de un conocimientoque resultó en acciones éticopolíticas.

La descripción de aspectos de su cosmogonía y de ritos, en este artículo, tiene el propósito de evidenciarcomo los saberes de los candomblés propician elementos para el ejercicio de la noviolencia. A partir de un trabajo etnográfico, intento demostrar que el ejercicio de la noviolencia no es una quimera, tampoco idealismo, sino más un modo de posicionamiento social mediante prácticas socio-políticas a través de un conocimiento complejo con sus consecuencias prácticas de dignificación de ciudadanos que participan de comunidades de candomblé.

\section{¡Hoy, vamos a divertirnos!}

El titulo es una frase muy extendida en los terreiros de candomblé, donde el propio sentido religioso de las ceremonias rituales integra la noción de fiesta, de regocijo por el encuentro con la divinidad, el orixá. Fiesta para recibir en el ayiê, la tierra, las divinidades que viven en el orun. Los terreiros se organizan, de la mejor forma que pueden, para exhibir un ambiente bellamente preparado para el encuentro con el orixá. En el terreiro se canta, se baila, se come -una verdadera fiesta. Este dicho también rememora el pasadocuando los esclavos cantaban sus cantos religioso en los intervalos de los trabajos rutinarios, en el campo, en el descanso, momentos en que se "permitía” expresiones lúdicas. 
Evidentemente que la comprensión de lo que hablaban entre ellos y en sus cantos, era poco perceptible, por estar en sus idiomas originarios africanos. Todavía el yoruba continúa como idioma utilizado en los candomblés, en los cantos religiosos, en los saludos a los orixás, en los nombres que las personas reciben, tras las iniciaciones, incluso con la utilización de palabras en el uso diario en los terreiros. Me acuerdo que en los primeros momentos de mi investigación, los participantes del terreiro Ilê Axé Ijexá Orixá Olufon me decían: “oye, me pase el omidudu”, y otro me solicitaba, “por favor tráeme el apoti” y así otras frases, cuya a palabra determinante estaba en yoruba y, por lo tanto, no podía comprender qué me solicitaban. Tuve que realizar las primeras anotaciones de que el omidudu era café, el apoti el banquillo de madera y, así tuve que aprender muchas otras palabras, hasta que formé mi primer glosario. No es difícil de imaginar que el idioma yoruba hubiera servido para el ocultamiento de situaciones, como una forma misma de resistencia.

Igualmente, la gente aprovechaba las fiestas de los santos católicos para hacer sus rituales religiosos. La tan conocidatransferencia de significados de santos católicos con los orixás, merece ser tenida en cuenta por ser un ejemplo significativo. En los pejis, especie de altares, preparado para el orixá Ogun, por ejemplo, se exhibía una estampa de Santo Antonio; en el del orixá femenino Iansã, la estampa de Santa Bárbara y así sucesivamente. Era un disfraz que les permitían expresar su creencia sin que sus dueños se diesen cuenta, de sus verdaderas intenciones. Abreu (2002:85), señala que esto deja claro que no es una actitud nada pasiva en relación a la religión dominante, sino una forma de apropiación, recreación y reinterpretación de la cultura dominante. Asimismo Limonta / (2009:31), expone que representa una estrategia de sobrevivencia cultural, un recurso de resistencia velado dentro de una estructura de dominación colonial. Keesing (1992) verificó que los Kwaio, de las islas Salomón, resistieron a las perspectivas del poder cristiano con el reconocimiento de sus categorías, pero alterando sus significados.

En el sur de Bahia, hasta hoy, se celebra un fiesta popular el "Caruru de Cosme e Damião”, en homenaje a los santos católicos gemelos, en la que se preparan comidas semejantes a las de los terreiros y que se ofrecen a los niños. En los terreiros es la fiesta de los a los Ibejis, que son orixás niños, también gemelos. Una permanencia del periodo del ocultamiento de orixás en santos católicos, que se integró a la vida de la gente de las ciudades sur bahianas.

Es Scott (2000) quien expone que las disposiciones de los poderes más inflexibles no son capaces de lograr una perfecta dominación de aquellos que concentran menos poder. Para el autor, la sumisión de los subalternos puede esconder la resistencia, que es lo que se verifica en el caso de los afro-brasileños que tuvieron que disimular, ocultar sus creencias en variadas formas que la creatividad les proporcionaba. Ya Comaroff (1985) señala que al analizarse el contenido de prácticas de resistencia, hay que observarse que no siempre plantean una amenaza inmediata, pero que minan y alte- 
ran cierta lógica. En el caso del candomblé, el camuflaje fue uno de los elementos que socavaron y alteraron la lógica del dominador, mientras que en apariencia había una “aceptación”del modelo católico.

De este modo, la simulación de aspectos de los saberes traídos en los cuerpos-sujetos de etnias africanas, posibilitó su supervivencia. Hasta hoy, oímos a los participantes de los terreiros, referirse a los rituales como un momento de diversión, que tampoco no tiene porque no ser, como observé, durante años, el placer y la alegría en vivenciar los rituales de un modo lúdico, lo que no minimiza para nada la fuerza de los actos. Asimismo, la vivencia de expresiones lúdicas a través de la música, la danza, los movimientos pausados o más agiles del cuerpo, dependiendo de lo que exige cada orixá, todo ello propicia el relax corporal, la risa, el movimiento gestual de cariño con el otro, así como el placer en compartir significados consensuados en performances rituales.

Este encaje del disfraz de saberes religiosos a través de expresiones lúdicas se dio porque es un tipo de conocimiento sin las delimitaciones del placer a determinadas situaciones y momentos propicios. Religión, en la concepción afro-brasileña, es también fiesta como bien señala Amaral (1998,2005), al defender la fiesta como elemento estructurante de esta religión. Esta interpretación de lo religioso es un ejemplo de las posibilidades creativas de los candomblés. La imbricación entre dimensiones del conocimiento fortaleceel diálogo entre los saberes en la vivencia estético-religiosa que valoralo bello a partir de la noción de una “estética de la acción” en la intersección entre los aspectos moral/correcto que se vincula al de lo bello y lo placentero, agradable, vividos en las acciones cotidianas (Overing, 2000). En este sentido, la risa, el placer, el bienestar son elementos que indican unposicionamiento que rompe con el sufrimiento para establecer la alegría como elemento de dignificación personal y colectiva. Una elección en el ámbito de la noviolencia que erige laexperiencia de la valoración de las sensaciones, de los sentimientos y de prácticas placenteros como un modo de expresiónético-estética.

El hecho de establecer la integración, ya anuncia la capacidad de dialogo entre las diferencias y, por lo tanto, es un ejercicio que posibilita la dinámica de la interrelación entre saberes, con sus lógicas propias, y posibilitando la ampliación del dialogo entre las distintas dimensiones del conocer. La integración de elementos socio-histórico-culturales puede permitir la rotura de posicionamientos hegemónicos que intentan homogenizar yeclipsar la vivencia beneficiosa que la diversidadpropicia.

\section{Dualidad no dicotómica}

Mientras que el pensamiento colonial hacía perceptible su poder por medio de las separaciones entre colonizador-colonizado, catolicismo-hechicería, santo-demonio, otra modalidad de conocimiento iba siendo (re)elaborada en las entrañas del segregacionismo. Las reinvenciones iban 
siendo construidas a partir de las interrelaciones/imbricaciones entre los conocimientos de lasdistintas etnias africanas, aunque los colonizadores portugueses las homogenizaban. El historiador Reis (1996:18) cuestiona la simplificación y homogeneización de la historia de los pueblos africanos enBrasil y expone que "los negros eran diferentes, los africanos eran diferentes y ellos tenían orgullo de esta diferencia. Esto ayudó a mantener la dignidad, afirmar su humanidad ante un régimen que los definían como cosa” (t.p.) Afirma, además que las diferencias eran significativas para tejer las redes de solidaridad, para establecer acuerdos o delimitar territorios hostiles.

En este sentido, tuvieron la capacidad para apropiarse y agregar divinidades de diferentes culturas y crear un panteón de dioses reunidos en un solo espacio, los terreiros de candomblé. Con esta capacidad para recuperar e integrar conocimientos, los afro-descendientes construyeron un modo de conocimiento en el cual la noción de dualidad no incluye la separación, una dualidad complementaria, por lo tanto. La dicotomía destruiría la noción de la coexistencia entre la materia y el espíritu, que es uno de los puntos focales del candomblé.

Durante mi trabajo de campo, estuve siempre atenta a las historias míticas, pues como se sabe, las creaciones mítico-simbólicas nos permiten comprender ciertos enfoques culturales. Citaré dos historias contadas por el babalorixá Katulembá, del Ilê Axé Ijexá Orixá Olufon, de la ciudad de Itabuna, en Bahia, pero también las encontré en los terreiros IlêAxéIjexáEjóAranfejú, IlêAxéOdéAladê, que son originarios del Ilê Axé Ijexá Orixá Olufon, así como en elterreirollêAxéOyáFunké, situados en la misma ciudad. Estos mitos nos permitenpercibir lo que es una dualidad no disyuntiva en el candomblé:

Cuenta la gente del terreiro que Oxum ${ }^{1}$ y Oxóssi se amaban apasionadamente y que ambos engendraron un hijo que nació mitad Oxóssi y mitad Oxum. Un día, Oxum llevó a la criatura a un río, lo sentó encima de una inmensa flor y se fue a hablar con sus amigos. Habló tanto que cuando regresó para recoger a su hijo no lo encontró. Lo que sucedió fue que el orixá femenino Iansã lo había encontrado, y creyendo que era un niño abandonado decidió adoptarlo. Años después, Iansã se enteró de que su hijo adoptivo, Logum-Edé, era el niño desaparecido de Oxum y decidió llevarlo para que conociera a su madre. Cuando Logum-Edé descubrió la riqueza del palacete de Oxum, expresó su deseo de vivir allí. Iansã había educado a LogumEdé con mucha libertad por lo tanto le encantaba conocer otros ambientes. Por ello, decidió conocer también a su padre, Oxóssi, a quien le expresó sus deseos. Oxóssi le prometió que, a partir de aquel momento, lo llevaría también a cazar. Con ello se acordó que LogumEdé compartiría periodos de tiempo unas veces con la madre, en el agua, y otras con el padre, en selva.

El orixáLogum-Edé, es un orixállamadometá (de mitad) pues congrega características de su padre y, a la vez, de su madre, Oxum. Incluso 
toda su configuración en colores, en las insignias simbolizan a los dos progenitores. Es un ejemplo de intercomunión simbólica entre los orixás Oxóssi y Oxum. Un diálogo entre contrarios en la configuración de otro ser, pero que genera su propia configuración, el orixá Logum-Edé que es distinto a sus padres, pero que contiene en sí ambas significaciones. Logum-Edé, por lo tanto, se configura en una integración y complementaridad de diferencias, siendo él mismo singular.

El siguiente mitoevidencia que ni siempre hubo una división entre los dos mundos, el ayiê y el orun, no estaban separados, pero había una prohibición de que el ser humano transitasehacia la dimensión de las divinidades. Una persona curiosa desobedeció a Oxalá, padre de los demás orixás, traspasando sus fronteras y originando la separación. Oxalá, muy molesto con la desobediencia, lanzó su bastón ritual, el opaxorô, y el mundo se dividió en dos, el orun arriba y el ayiê, abajo. Esto permitió que los orixás continuasen pudiendo transitar entre los dos mundos, en cambiolos seres humanos solo pueden hacerlo, completamente, cuando mueren.

Observando estas elaboraciones míticas y las acciones cotidianas de los terreiros, pude constatar que los actos y relaciones de la gente de candomblé es buscar mantener la conexión entre las dualidades. Los rituales son realizados con esta intención. Todo pasa por el intento de mantener la conexión constante y produciendo, así, un conocimiento integrador dónde las relaciones cuerpo-mente, orixá-humano/a, ayiê-orun, son singularidades que se complementan.

También se pude ejemplificar con el orixáIroko, que vive en un árbol “morera blanca africana” (Milicia Excelsa) que en Brasil hubo la substitución por el Ficus Doliaria, a punto que este árbol sea considerado el proprio orixá, un ejemplo de integración con elementos de la naturaleza. Por cierto esta visión de unión entre los elementos de la realidad, sea entre dioses, seres humanos, elementos de la naturaleza y cosas, generó un tipo de conocimiento que provocó incomprensiones, rechazos y en consecuencia alejamientos y prejuicios, todavía presentes en la actual sociedad brasileña.

La cuestión de la vivencia de un modo dual, sin ser dicotómico, implica diversas consecuencias, como las nociones singulares de divinidad y decuerpo, en las cuales existe una relación de gran proximidad entre el ser humano y el orixá, como veremos a seguir. Es una noción antagónicaa ciertas posicionesbasadas en la separación. Al establecer un saber en lo cual la integración es la palabra clave, es una decisión de los grupos de candomblé que definen sus modos de estar en la dinámica social, defendiendo el derecho a la diferencia y el respeto a la alteridad.

La manera como lo hacen, resistiendo a todo el tipo de discriminación, conlleva la superación de la intolerancia e incomprensión mediante la experiencia del bienestar de sus miembros. Es un ejemplo que confirma la dignificación de una experiencia comunitaria que prioriza la noviolencia. Incluso en los momentos más difíciles, los candomblés supieron construir 
estrategias creativas para confirmar la diversidad de un saber mediante un enfoque filosófico, existencial, así como también definió posicionamientos ético-políticos.

\section{El orixá}

La divinidad afro-brasileña es antagónica a los cañones cristianos. Para comprender su concepción debemos referirnos a la inexistencia, en el candomblé, de la separación entre el bien y el mal. Se considera que existen dos energías distintas, contrapuestas, pero que forman parte de una misma realidad, pudiendo interpretarse también como luz y sombra. Una realidad que suscita que los orixás, así como los humanos/as, tengan que encontrar su punto de equilibrio entre estas dos fuerzas"sacar lo mejor de las dos”, como se suele decir en los terreiros. Los orixás, por consiguiente, expresan contradicciones, conflictos, ambigüedades. Pueden expresarse con suscaras amables, comprensivas, amigables, pero igualmente pueden enfadarse, regañar, ser demasiado estrictos, exigentes, etc. Lo que la gente intenta es que estén siempre contentos, en equilibrio, a gusto en las fiestas y en sus vidas, pues se considera que así sereciben mejor sus bendiciones.

En este sentido, imaginemos entonces lo que pueden haber interpretado los primeros misioneros, que iban paso a paso con los colonizadores, al encontrarse con una concepción de divinidad que es un trickster, un orixáburlón, que puede llegar a hacer daño con sus trampas, sus artimañas, si algo no le agrada, como es el caso de Exu. Además, por ostentar la insignia de un tridente, del falo erecto como uno de sus símbolos relativos a la sexualidad y a la reproducción humana, además de sus colores, el negro y el rojo. Dependiendo de la perspectiva por la cual se mire este tipo de divinidad, podría ser juzgada como una descripción demoníaca.

Tampoco sería comprensible una divinidad que baila, canta, se alimenta, se divierte, intercambia secretos, sufre los dolores de la gente, enseña medicinas, etc. Ni una divinidad que se fusiona con el ser humano en el momento de trance-posesión ${ }^{2}$ cuando se incorpora en el cuerpo del fiel. Una concepción de divinidad que contiene en si las contradicciones en un juego constante para s lograrse el equilibrio. En el candomblé sus divinidades están integradas en la dinámica de la vida y simbolizan la fecundidad, la abundancia, la enfermedad, la curación, etc. Ejemplos como el de Exu, pueden haber sido generadoresde recelos e incomprensiones. Todavía, hoy, algunos sectores de la sociedad brasileña consideran el candomblé como una forma de hechicería. Por consiguiente, hablar de resistencia y persistencia cultural también presupone una invitación a que se revisen ciertos patrones ideológicos y epistemológicos, que pueden ser utilizados para justificar la violencia tanto física como cultural.

Deconstruir ciertos paradigmas que generan la intolerancia puede ser una de las vías para la defensa de las formas alternativas de construcción socio-cultural. Este planteamiento posibilita el derecho a la elección de 
modos diferenciados de experiencias comunitarias con sus implicaciones ético-políticas, como es el caso de los terreiros de candomblé. Dichos grupos religiosos corroboran un tipo de conocimiento y sus prácticas correspondientes que valoran la paz.Incluso una de las divinidades del panteón afro-brasileño, el orixá Oxalá, el dios que es responsable de crear el mundo y los seres humanos, tiene el color blanco como uno de sus significaciones simbólicas de paz, que se concreta en las vestimentas, tanto de este orixá como en las de los fieles de los candomblés. También el animal que corresponde a esta divinidad es una paloma, que simboliza la paz.

\section{Cuerpo - morada de lo divino}

El filósofo Nietzsche (1997, 1997b, 2005), ha sido uno de los primeros en alertar sobre la mala compresión del cuerpo mediante la exaltación del espíritu. Señala que las perspectivas dualistas estaban cargadas de intereses religiosos y morales que contribuyeron a la negación del cuerpo.Alerta de que no existe ninguna idea o realización que no se relacione con el cuerpo, lo que implica que el cuerpo no puede ser considerado de forma aislada, independiente de la existencia, sino que debe ser contemplado como un donador de sentido de la realidad. Destaca, aún, que no se puede conseguir una desincorporación en el proceso de pensar ya que es por medio del cuerpo que se piensa.

Su propuesta es un llamamiento para repensarse el modelo de racionalidad que excluyó al cuerpo del mundo empírico y que lo alejó de la sensibilidad del mundo y de la vida. Nietzsche (2005:59) en Así hablaba Zaratrusta dijo "Quien está despierto y consciente exclama: Todo yo soy cuerpo y ninguna otra cosa. El alma solo es una palabra para una partícula del cuerpo. El cuerpoes un gran sistema de razón”, una defensa a la racionalidad material del cuerpo.

Es Merleau-Ponty (1999 [1945]) que da seguimiento al planteamiento nietzscheano cuando refuta la metafísica cartesiana y la visión cientificista, proponiendo el (re)encuentro de la experiencia, lo cual fuerza el (re)pensar sobre las disyunciones,la superación del dualismo cartesiano entre cuerpo y alma para el regreso al mundo de la vida, cuyo punto de partida es la propia existencia fenoménica humana. Pone énfasis que el ser humano está inserto en el mundo y es en el mundo que conocemos cundo señala que "el mundo no es aquello que yo pienso, pero aquello que yo vivo...” (1999:14 [1945]), (t.p).

Perfila, así, la centralidad del cuerpo en relación a la percepción y que la subjetividad sea contemplada como una conciencia encarnada - el ser en la existencia y el cuerpo como instituyente del conocimiento. El cuerpo es lo que nos posibilita conocer, donde el cuerpo es nuestro vehículo en el mundo y no lo podemos conocer por medio del pensamiento discursivo, hay que vivirlo. 
Dando continuidad a estaperspectiva, el antropólogo Michael Jackson (1983), que también se aproxima a los planteamientos de Marcel Mauss,indica que el cuerpo se constituye a sí mismo como body subject, dado que el movimiento corporal no es una realidad simbólica, si no la propia realidad y que el conocimiento proviene de la implicación práctica y sensual y no de principios genéricos. Destaca que la experiencia del ser humano se asienta en movimientos corporales en el ambiente material y social y acentúa como las formas del uso del cuerpo se determinan por nuestra relación con seres y objetos. Csordas (1990:5) igualmente considera el cuerpo como el "sujeto de la cultura", cuyo concepto de embodiment objetiva eclipsar la idea de que lo social se inscribe en el cuerpo, al salir en la defensa de que es el propio cuerpo el campo de la cultura (ground of culture) $(1990,1994,2008)$.

Como se sabe, el cuerpo es uno de los temas que vienen movilizando a muchos investigadores, de distintas áreas del conocimiento. Traer estas propuestas sobre el cuerpo ha sido motivado por la proximidad de estas propuestascon la noción y vivencia de la corporalidad en los candomblés, donde el cuerpo es uno de los puntos relevantes, incluso puedo afirmar que es una religión corporeizada, pues todo pasa por el cuerpo, configurándolo como uno de sus sustentos.

En los terreiros de candomblé la gente vivencia en sus cuerpos la estrecha relación con la divinidad, con la existencia del orixá principal de cada persona, que vive en el ori, la cabeza, cuyo cuerpo pasará por rituales para fijarlo, en este punto. Todo está preparado para el encuentro con el orixá por medio de una estética exuberante en los ambientes, en las vestimentas y, principalmente, en las de los orixás, con explosión de colores, ornamentos, insignias, todo ello con una simbología profusa.

Cuando los orixás están incorporados, hay un momento en que se permite a toda la gente, fieles e invitados, presentes en los xirê $\hat{e}^{3}$, se acerquen, abracen y hablen con la divinidad. Estos momentos, de íntima relación con el orixá, generan ansiedad, emoción, expresiones alegresbien visibles en los gestos y movimientos corporales. La divinidad vive con la gente tanto durante el trance-posesión, como después ya que no se produce una discontinuidad cuando el trance se finaliza. Todo el ambiente del terreiro se organiza para quela energía del orixá permanezca, con la intención de no dejar margen a fisuras entre las dimensiones espíritu-materia.

Se puede sentir la presencia del orixá en la red comunitaria que semantiene en los actos cotidianos, en los ebós, las ofrendas, en los pejis, lugares donde se colocan los objetos de los orixás, en los comportamientos, en los símbolos corporales, en los rituales, etc.Sin olvidar que el propio cuerpo del fiel es su morada. El cuerpo alberga la divinidad y los rituales para la iniciación son con este propósito, o sea, sensibilizar el cuerpo para el encuentro con la divinidad, para establecer una relación más estrecha de cada fiel con su orixá de cabeza. 
“Hacer la cabeza” es un ritual de gran complejidad que suele tardar un mínimo de veintiún días de reclusión en los terreiros. Es un ritual que simboliza tanto la muerte como como el renacimiento simbólico del sujeto. El cuerpo-persona, tiene que desprenderse de un pasado no deseado para poder ratificar los paramentos establecidos por el candomblé. Con ello una nueva identidad es construida y, incluso, el fiel recibe otro nombre, en yoruba, que marca su relación con el origen africano y reconfirmado en el presente.

Como se observa, la concepción de una divinidad que vive en el cuerpo de una persona, es incomprensible para ciertos paradigmas. Como Nietzsche alertó, dichos paradigmas pueden estar cargados de una cierta moralidad y de visiones religiosas que propugnan la negación del cuerpo, de la separación entre lo divino y lo humano. No es nada sencillo que ciertos sectores sociales comprendan y acepten la experiencia religiosa en la cual el cuerpo es el gran protagonista, mucho menos que la divinidad se exprese mediante la interunión con el cuerpo humano. La experiencia que valora la paz implicala comprensión y respeto a la riqueza social que adviene de la diversidad, que puede ser desconcertante, para algunos, pero que debe tener como punto de apoyo la justicia a la cual los grupos sociales tienen el derecho a la defensa de sus parámetros y perspectivas.

\section{Poder sacralizado}

En ladinámica de los grupos de candomblése plasmó un poder jerárquico-sacralizado, constituido en la estrecha relación entre el ser humano y la divinidad, el orixá. La autoridad, por lo tanto, es elegida y sostenida por el orixá que se incorpora en su cuerpo y pasa a ser el propio orixá en presencia. Los líderes, babalorixá, cuando es hombre, oialorixá, cuando es mujer, alberganen sus cuerpos las señales de lo divino. Solamente los que entran en trance pueden llegar a ser un babalorixá o una ialorixá, exactamente porque es la capacidad de entrar en trance-posesión lo que le permite alcanzar esta posición dentro del grupo.

Es un tipo de autoridad ungida por la divinidad, pero también es la que sabe más, un saber-poder, un tipo de conocimiento que se potencia con el poder que le asigna el orixá. Cuando alguien entra en trance, el grupo considera que, en aquel momento, no es la persona allí presente, pero sí el orixá que se encuentra en fusión en el cuerpo del otro, de hecho una divinidad incorporada. En estos momentos, los orixás pueden aconsejar, contestar preguntas, también reprenderu orientar a la gente, solicitar ciertas acciones, abrazar, indicar medicaciones, exigir algo o alguna acción. Es un honor para el grupo cuando los orixás vienen a convivir con la gente y por esto se organiza la fiesta para recibirlos.

Los grupos de candomblé construyeron un tipo de saber-poder y un ordenamiento social que requiere una serie de obligaciones, prohibiciones, conductas comportamentales y, todo ello, mediante una simbología 
consensuada que permite mantener la cohesión grupo, con la respectiva obtención de beneficios por el grupo y de un modo individualizado. Aunque la fuerza de la autoridad sea muy evidentey la cantidad de reglas comportamentales es impresionante, los ordenamientos son bien aceptados por sus miembros, así como la fuerza de la autoridad, sacralizada por el orixá, que el grupo acata. Preguntando sobre ello a una abiã, un fiel en el primer nivel jerárquico, del Ilê Axé Ijexá, así dijo:

Cuando venimos a formar parte de la comunidad, sabemos lo que nos exigen, las múltiples obligaciones e, incluso, nuestro “padre”, refiriéndose al babalorixá, es muy exigente, quiere todo muy bien hecho, pero si no es así no tendríamos las cosas bien organizadas. Los orixás nos ayudan mucho, pero para ello tenemos que contar con la responsabilidad de todoslos hermanos. Ya sabemos cómo es la gente, si no hay un pulso fuerte las cosas suelen no salir bien.

Declaraciones como esta son frecuentes, que demuestran que la autoridad es sostenida por el grupo. El deseo de cambio puede concentrarse en alguna característica personal del babalorixá o de la ialorixá, en el sentido de exigir menos, de escuchar más a la gente, por ejemplo, pero nunca hay alguna alusión a la disminución del poder de la autoridad ungida por la divinidad. Percibí que lo beneficioso en términos de salud, de mejoría de vida, en varios ámbitos, vivir en un ambiente solidario, sentirse querido, tener las peculiaridades personales respetadas, entre otros, todo ello supera cualquier incomodidad en términos del poder jerárquico instituido.

Resistir tampoco presupone una dirección inversa a un tipo de poder al que se resiste, con la supuesta creación de formas más abiertas. Me pregunto si la permanencia de un poder jerarquizado tenga sido solamente por una reproducción a un modelo que ya se conocía, por las experiencias anteriores a la colonización. Creo que tenemos que ir más allá de una sencilla implantación de un modelo, pero tampoco quiero minimizar la fuerza de las experiencias pasadas. Pienso en términos más de su manutención, considerándose que las propuestas pueden modificarse con la experiencia. En este caso, permanece, hasta hoy, la fuerte jerarquía en los candomblé. Las muchas historias que escuché es que en tiempos pasados los terreiros solían ser más rigurosos. Lo cierto es que la jerarquía es defendida por sus participantes.

La elección por un tipo de organización jerárquica, con una gran cantidad de exigencias comportamentales, obediencia, incluso el aprendizaje de gestos de reverencia a las autoridades puede que sea una de las respuestas a situaciones de desprestigio, cuando la ritualización jerárquica “impone respeto” como me comentó un ogãalabê, un cargo masculino con múltiples funciones. Otro elemento significativo se refierea que no es cualquier tipo de jerarquía sino a partir de la sacralización mediante la vía del poder del orixáque refuerza el poder jerárquico.

Además, el líder tiene que conocer aspectos de un amplio conocimiento y este saber es utilizado en beneficio de todos, incluso de personas 
externas a la comunidad, que acuden a los terreiros en busca de ayuda, ya sea en términos de salud, afecto o de subsistencia, los clásicos tres anhelos. Curar ciertos males, una depresión, por ejemplo, saber orientar, aconsejar, escuchar, servir de mediador entre el fiel y la divinidad, son características exigidas a este tipo de autoridad. Es una manutención de un poder sacralizado, pero con delimitaciones claras de las bendiciones que ello puede propiciar a la gente.

Igualmente, no existe la posibilidad a los que resisten a este tipo de poder garantizado por la fusión humano-divina. Aquellos que se oponen no tienen espacio en los grupos y terminan por solicitar su salida,como presencié algunas veces. Se constata que la defensa al poder jerárquicosacralizado se realiza por las ventajas que el candomblé significa en la vida de sus participantes.

Los fieles son unánimes en afirmar que el candomblé les exige mucho, que toda sus vida pasó a ser dedicada a ello, que la cantidad de prohibiciones e interdicciones no es fácil de llevar, pero todo ello compensa como en la declaración de la abiã Lilia, citada en mi tesis Santos (2013:335):

No es fácil seguir todo rigurosamente organizado, mantener todo muy bien cuidado, estar atenta para no olvidarme de lo que tengo que hacer conmigo misma, con la casa, con todo el grupo, con los orixás. Pero después que todo está hecho, la sensación es de gusto, de placer de encontrarme con mi padre Xangô, de sentir su fuerza, de recibir su abrazo, me siento otra, me siento muy bien.

Como se observa en esta declaración el afecto, el abrazo, el gusto de encontrarse el orixá Xangô, la proximidad con ello cuando le llama cariñosamente "mi padre”, que son aspectos que juegan un papel muy significativo para la gente en esta religión. Seguramente la configuración en términos de una familia representa uno de las motivaciones para la permanencia de la gente en los grupos, que le permite el encuentro con el otro, con el grupo, consigo mismo y con el orixá. La resistencia de un modo de vida que resignifica y permite la construcción de nuevasidentidades. Hall señala (2006:13), que en la medida que los sistemas de significación y representación culturales se multiplican, existe la posibilidad de confrontar múltiples identidades.

\section{Consideraciones finales}

La importancia de una “descolonización de la mente” como diría el escritor y ensayista Keniata NgugiWaThiong’o es un alerta válida para todos. Costa (2006) señala la importancia de las desconstrucciones de los esencialismos en las nociones de las diferencias humanas, que los estudios poscoloniales proponen, lo que también presupone la reivindicación a la revisión del modelo de modernidad excluyente. Estudiar la epistemología del conocimiento religioso afro-brasileño es un intentode avanzar en esta dirección. 
Mi intención ha sido poner de manifiesto que el candomblé instituyó un modelo de conocimientoque requiere atención, con la reivindicación de la necesaria desconstrucción de posiciones discriminatorias, cuando lo coloca simplemente en el ámbito de la fe, considerado como una construcción de aquellos que son "creyentes", como si las religiones no fuesen espacios de una arquitectura de saberes. El conocer integrador genera la atención al otro, que necesariamente implicadiálogos interculturales y que posibilita la ampliación de los modos de interpretación de la realidad. En este sentido, la construcción de un saber afrobrasileño es una alternativa tanto en términos de ciudadanía como de transformación de la política, que pone en discusión formas hegemónicas de poder. La construcción de una alternativa religiosa es también, por lo tanto, un ejercicio de ciudadaníaque pone en evidencia consideraciones político-ideológicas que no reconocen la diversidad, así como aquellas que transitan bajo parámetros más humanitarios.

Actualmente, las políticas educacionales brasileñas consideraron la importancia de los aspectos históricos y de conocimiento, tanto de los africanos como de sus descendientes, para la formación de la ciudadanía nacional, a punto de transformar en ley la incorporación de los estudios afro-brasileños en el plan de enseñanza nacional, ampliada, posteriormente, para estudios de la cultura indígena. Con esto se evidencia que el ejercicio de la noviolencia por parte de los grupos de candomblé, consiguió lograr el reconocimiento de su importancia para la construcción identitaria nacional, un indicativo evidente de un cambio social que transformó la política educacional nacional, concretando, así, las posibilidades del dialogo intercultural y/o de saberes.

Un espacio religioso va más allá que un grupo de fe. Lo que el terreiro genera es un manantial de posibilidades en términos de salud, de convivencia, de solidaridad, de estética, de mitología, de organización, cuidado del cuerpo, respeto a los mayores, etc. La riqueza que se encuentra en sus elaboraciones evidencia que es un lugar de muchas posibilidades, un conocer complejo, que conlleva un estilo de vida y una sociabilidad propia del grupo erigidas a partir de la interdependencia de todas la cosas. Una cosmovisión marcada por un amplio simbolismo y de una concepción de divinidad que vive en el propio cuerpo de los fieles. Todo ello por una comprensión filosófica de dualidad no dicotómica que permite las integraciones y las complementariedades.

Mientras nos debatimos para romper las dualidades, los grupos de candomblé tuvieron la capacidad de preservar resignificando dinámicamente concepciones no disyuntivas, traídas en los cuerpos-sujetos de etnias africanas. La cuestión no es solamente de observarse lo interesante que es el fenómeno del trance-posesión, por ejemplo, sino más bien comprender qué rol juega en la dinámica social de estas comunidades y lo que ello significa en la vida de las personas, con implicaciones para el bienestar físico-psíquico-emocional. 
La existencia de los candomblés nos exige situarlos como espacios de resistencia y persistencia cultural de un conocimiento integrador. Es tener en cuenta que las religiones generan saberes que permiten que la gente se cure, se encuentre consigo misma, mantenga lazos de amistad, siéntase protegidas, en una red de solidaridad y atención mutua de unos con los otros. Son grupos comunitarios-familia, en los cuales lo divino viene abrazar a la gente, pudiendo reprobar duramente y exigirle ciertos comportamientos, pero la persona siente que lo hace porque le quiere ayudar.

Es una religión que es vivida intensamente en el cuerpo y por esto la gente genera prácticas para cuidar del cuerpo porque "un cuerpo descuidado la divinidad no vive en él”, como suelen decir. Laconstrucción identitaria en la modalidad de la integración de este conocimiento, no deja de ser uno de los puntos de resignificación y dignificación interpersonal ante sí misma y en la convivencia con los demás, al confrontarse con sus otras identidades en sus vidas ordinarias, en la sociedad más amplia, que les demandan otros roles sociales.Además, es una religión que forma parte de la historia brasileña de lucha de los oprimidos frente a un poderrepresivo, pero que supo construir un complejo conocimiento a través de la noviolencia. 
Polis, Revista Latinoamericana, Volumen 15, $N^{\circ}$ 43, 2016

\section{Notas}

${ }^{1}$ Oxum es el orixá femenino de las aguas dulces, de la riqueza y fertilidad. Los demás orixás en este mito son Oxóssi, que es la divinidad de la selva y de la caza y Iansã que representa las tempestades y los vientos.

${ }^{2}$ Sobre el trance y la posesión espirituales, estoy de acuerdo con Rouget (1985) al considerarlo una capacidad psicofisiológica innata y cuya variabilidad se observa dependiendo de las diferencias culturales que lo condicionan. Trance y posesión son manejados por diversos autores como sinónimos o disponiendo una diferencia entre ambos. La posesión normalmente secontempla como una especie de trance en el que se produce la in-corporación de seres espirituales en el cuerpo de un sujeto y con alteraciones físicas visibles. Por mi parte, opto por utilizar el trance en su sentido más amplio, de modo que incluya la posesión y, por esto, utilizo el término trance, o trance-posesión, con el mismo sentido.

${ }^{3}$ Es un ritual realizado mediante una gran rueda de danza acompañada de un conjunto de ritmo y cantos a los orixás . 


\section{Bibliografía}

Abreu, Marta (2002), “Religiosidade popular, problemas e histórias”, en Lima, da G. Lima, Honorato, C. Teirxeira, et al, (orgs.), História e Religião, Faperj/Mauad, Rio de Janeiro, pp. 83-90.

Amaral, Rita (1998), “AwonXirê! A festa de candomblé como elemento estruturante da eeligião”, en Moura, Carlos Eugênio M. de M (org.) Leopardo dos Olhos de Fogo, Ateliê, São Paulo, pp. 85 -118.

Ídem, (2005), Xirê! O modo de crer e de viver no candomblé, Pallas, Rio de Janeiro; Educ, São Paulo.

Araújo, J. N. Garcia de (2014), “Figuras de resistência”, Caderno de Psicologia Social do Trabalho, vol. 17, n.1, São Paulo, pp. 33-42.

Barros, José Flávio Pessoa de; Teixeira, Ma Lina Leão (2000), “O Código do Corpo: Inscrições e Marcas dos Orixás”, en Moura, Carlos E. Marcondes de (org.) Candomblé: Religião de Corpo e Alma, Pallas, Rio de Janeiro, pp.103-138.

Canclini, N. García (2013), “¿De qué hablamos cuando hablamos de resistencia?”, Revista Arquis, Universidad de Costa Rica, UCR, vol. 2-1, n. 3, pp.1-23.

Comaroff, Jean (1985), Body of power, spirit of resistance: the culture and history of a South Africa people, The University of Chicago Press, Chicago/ London.

Costa, Sérgio (2006), Dois Atlânticos: teoria social, anti-racismo, cosmopolitismo, Editora UFMG, Belo Horizonte.

Csordas, Thomas J. (1990), “Embodiment as a paradigm for anthropology”. Ethos, v.18, n.1,pp. 5-47.

Ídem,(1994), (ed.), Embodiment and experience:the existential ground of culture and self, Cambridge University Press, Cambridge.

Ídem, (2008), Corpo/signficado/cura, UFRGS Editora, Porto Alegre.

Ferreti, S. Figueirdo (1995), Repensando o sincretismo: estudo sobre a Casa das Minas, Edusp/Fapema, São Paulo.

Goldman, Marcio (2005), "Formas do saber e modos do ser: observações sobre multiplicidade e ontologia no candomblé”. Religião e Sociedade, vol. 2, n.25, pp. 102-120.

Hall, Stuart (2006), Identidades culturais na pós-modernidade,11 ${ }^{\mathrm{a}}$ ed., DP\&A, Rio deJaneiro. 
Polis, Revista Latinoamericana, Volumen 15, $N^{\circ}$ 43, 2016

Jackson, Michael (1983), “Knowledge of the body”, Man,vol. 18, n. 2, pp. 327- 345.

Limonta, I. delas Mercedes Hodge (2009), Cultura de resistência e resistência de uma identidade cultural: a santería de Cuba e o candomblé brasileiro. Tesis doctoral en Historia, Universidade Federal da Bahia, UFBA, Salvador.

Martínez, Mario López (2004), “Noviolencia para generar câmbios sociales”, Polis [En línea], 9, DOI: 10.4000/polis.7326.

Merleau-Ponty, Maurice (1999 [1945]), Fenomenologia da percepção, MartinsFontes, São Paulo.

Nietzsche, Friedrich W. (1997), La genealogía de la moral, Alianza, Madrid.

Idem, (1997b), Más allá del bien y del mal, Alianza, Madrid.

Ídem, (2005), Así hablaba Zaratustra, Edaf, Madrid.

Overing, Joana (2000), “The Efficacy of Laughter: The Ludic Side of Magic within Amazonian Sociality”, en OVERING, Joanna; Passes, Alan (coords.) The Anthropology of Love and Anger: The Aesthetics of Conviviality in Native Amazonia, Routledge, London/New York, pp. 64-85.

Parés, L. Nicolau (2007), A formação do candomblé: historia e ritual da nação jeje na Bahia, Unicamp, Campinas.

Reis, J. José (1996), “Identidade e diversidade étnicas nas irmandades negras no tempo da escravidão”.Tempo, vol. 2, n.3, pp. 7-33

Ídem,(2008), Domingos Sodré, um sacerdote africano: escravidão, liberdade e candomblé na Bahia do século XIX, Companhia das letras, São Paulo.

Reis, J. José; Silva, Eduardo (2005),Negociação e conflito: a resistência negra no Brasil escravista, Companhia das Letras, São Paulo.

Rouget, Gilbert (1985), Music and trance: a theory of the relations between music and possession, TheUniversity of Chicago Press, Chicago.

Santos, M. Consuelo Oliveira (2013) La dimensión estética de la salud en el candomblé IlêAxéIjexáOrixaOlufon - Sur de Bahia Brasil. Tesis doctoral en Antropología Social y Cultural, Universitat Rovira i Virgili, URV, Tarragona.

Scott, James (2000), Los dominados y el arte de la resistencia. Discursos cultos, Era, México D.F. 
Turner, Víctor W. (1988 [1969]), El proceso ritual: estructura y antiestructura, Taurus, Madrid.

Keesing, Roger M.(1992), Custom and confrontation: the kwaio struggle for cultural autonomy, The University of Chicago Press, Chicago/London.

Recibido: 30.01.2016

Aceptado: 05.04.2016 